\title{
Influence of Three Diatom Aldehydes against the Dengue Vector Aedes aegypti (Diptera: Culicidae)
}

\author{
Raunak Dhanker1', Archana Tiwari², Hans-Uwe Dahms³, Ram Kumar4*, Jiang-Shiou Hwang5 \\ ${ }^{1}$ School of Basic and Applied Sciences, GD Goenka University, Gurugram, India \\ ${ }^{2}$ Diatom Research Laboratory, Amity University, Noida, India \\ ${ }^{3}$ Department of Biomedical Science and Environmental Biology, Kaohsiung Medical University, Taiwan \\ ${ }^{4}$ Centre for Environmental Sciences, Central University of Bihar, Patna, India \\ ${ }^{5}$ Institute of Marine Biology, National Taiwan Ocean University, Taiwan \\ Email: raunakbiotech@gmail.com, panarchana@gmail.com, hands@kmu.edu.tw, ‘ramkumar@cub.ac.in, jshwang@ntou.edu.tw
}

How to cite this paper: Dhanker, R., Tiwari, A., Dahms, H.-U., Kumar, R. and Hwang, J.-S. (2019) Influence of Three Diatom Aldehydes against the Dengue Vector Aedes aegypti (Diptera: Culicidae). American Journal of Plant Sciences, 10, 1749-1762.

https://doi.org/10.4236/ajps.2019.1010124

Received: September 3, 2019

Accepted: October 15, 2019

Published: October 18, 2019

Copyright $\odot 2019$ by author(s) and Scientific Research Publishing Inc. This work is licensed under the Creative Commons Attribution International License (CC BY 4.0).

http://creativecommons.org/licenses/by/4.0/

\begin{abstract}
Larvae of several mosquito species being vectors of infectious diseases as adults feed on algae in their natural habitat. Algal food comes along with bioactive compounds providing important chemical defenses against predators, competitors, and pathogens. Aedes aegypti (Linnaeus in Hasselquist, 1762 ) is commonly called yellow fever mosquito, being a vector of several fatal diseases such as dengue fever, zika fever, chikungunya, and yellow fever. In this study, we have investigated the susceptibility of larvae of $A$. aegypti mosquitos to three most commonly studied diatom aldehydes-2-trans, 4-trans heptadienal (HD), 2-trans, 4-trans octadienal (OD), and 2-trans, 4-trans-decadienal (DD). In the experiments, instar-I and -IV larvae of Ae. aegypti were exposed to above PUAs for different time intervals. Both mosquito instars were susceptible to $\mathrm{HD}, \mathrm{OD}$ and $\mathrm{DD}$. Instar-I larvae were more susceptible compared to instar-IV. The percentage of mortality of both instar larvae was higher with greater concentrations of each tested PUA. Furthermore, mosquito larvae, tested on DD applied medium was estimated to be more susceptible followed by OD and then by HD. After $24 \mathrm{~h}$ observation, LC 50 value was the lowest for DD $(0.64 \mu \mathrm{L} / 40 \mathrm{~mL})$, followed by $\mathrm{OD}(0.88$ $\mu \mathrm{L} / 40 \mathrm{~mL})$ and $\mathrm{HD}(1.47 \mu \mathrm{L} / 40 \mathrm{~mL})$ respectively. In current scenarios, our results suggest that natural aldehydes from diatoms could provide promising public health benefits by controlling mosquito vector populations. Furthermore, an in-depth study of the interaction between primary producers and mosquito immatures in nature could provide several advancements in vector control research and management.
\end{abstract}

${ }^{\star}$ Corresponding author. 


\section{Keywords}

Mosquito Larvicidal Compounds, Mosquito Control, Diatom Bioactive Compounds, Aldehydes, Public Health Management

\section{Introduction}

The mosquito Aedes aegypti is instrumental in the transmission of many diseases such as dengue, chikungunya, and yellow fever caused by viruses that are transmitted to humans. These caused approximately, 3.9 billion infection cases and thousands of deaths worldwide [1] [2]. Although Ae. aegypti depends on rainfall for breeding, many types of household containers, such as clay jars, bird pots, drums, tanks, discarded tires, plant or flower containers are major breeding sites of this species in urban and suburban areas [3] [4] [5]. An increasing number of studies followed how to optimally control the dengue mosquito vector $A e$. aegypti [6] [7] [8].

Synthetic insecticides are used worldwide to control mosquito adults as well as their immatures. However, the existing chemical-based methods have several disadvantages. They are either expensive, not ecofriendly, and contribute towards greater cases of emerging resistance coupled with detrimental impact on the health of humans and aquatic organisms [9] [10]. Elevated resistance to microbial biocontrol agents employed in mosquito control is emerging worldwide [11] [12]. The negative impact of synthetic insecticides on non-targeted flora and fauna has facilitated exploratory studies as natural products like phytochemicals [8] [13].

Algae are the major part of the diet of aquatic organisms [14] [15] [16] and larvae of many mosquito species [17] [18]. Microalgae produce so many types of low molecular weight metabolites such as $2 \mathrm{E}, 4 \mathrm{E}$-heptadienal; 2E,4E-octadienal; 2E,4E-2,4,7-octatrienal 2E,4E,7Z-decatrienal and 2E,4Z,7Z-decatrienal. Besides this, few benthic diatom species have been reported to produce many unique low molecular weight compounds such as the oxo-acids

12-oxo-(5Z,8Z,10E)-dodecatrienoic acid (12-ODTE) (5) and

9-oxo-(5Z,7E)-nonadienoic acid (9-ONDE), which has been identified to inhibit invertebrate embryonic development [19]. Recently, some studies showed that algal bioactive compounds also function in the defense against predators, competitors, and pathogens alike [20] [21]. This way they can also affect ecosystem functioning in the plankton [22]. Mounting evidence is available from toxic effects of algae on aquatic stages of mosquitoes [18] [23]. The inhibitory potential of algae is provided by secondary metabolites such as polyunsaturated aldehydes (PUAs) and other metabolites derived from the oxidation of fatty acids (collectively termed oxylipids). This may happen after cell damage as it occurs to algae during the feeding process of grazers [16] [19] [24] or lysed from senescent cells during bloom periods [25]. These defensive allelopathic compounds are second- 
ary metabolites as they apparently not directly take part in the primary metabolism. Many algal species especially cyanobacteria have been shown to produce compounds that are also toxic to mosquito larvae [26] [27].

For the first time, Wendel and Juttner [28] isolated PUAs (Polyunsaturated aldehydes) as secondary metabolites from the freshwater diatom Melosira varians. Their biological activity was subsequently identified by Miralto and co-workers [29] in the marine diatom Thalassiosira rotula. PUA

2-trans,4-transdecadienal (DD), 2-trans,4-transoctadienal (OD) and

2-trans,4-transheptadienal (HD) was shown to cause anti-proliferative activities in small-and large-sized organisms [19] [30]. Chemical structure of all the three PUAs has been shown in Figure 1. HD and OD may act as precursors of microalgal sex pheromone, stimulate cytokine secretion in leucocytes and modify the activity of tumar causing factors [19]. Several studies revealed that DD, OD and HD inhibit the embryonic development and affects the following endpoints substantially, so in marine invertebrates like copepods where egg viability, hatching success, larval fitness, and survival was affected [29] [31] [32] [33] [34]. Thus, inhibitory or deterrent activity of some algal species may be a natural and suitable way to control the development of mosquitos.

Algal derived bioactive compounds have been reported from benthic and freshwater algae. However, until recently, only a few studies have shown larvicidal activities of some microbial algal species such as cyanobacteria [35]. No information is available about the larvicidal activity of diatom aldehydes on mosquito larvae. We here assessed the susceptibility of I and IV instar larvae of Aedes aegypti to three most commonly studied diatom PUAs:

2-trans,4-trans-decadienal (DD), 2-trans,4-trans-octadienal (OD), and

2-trans,4-trans-heptadienal (HD).

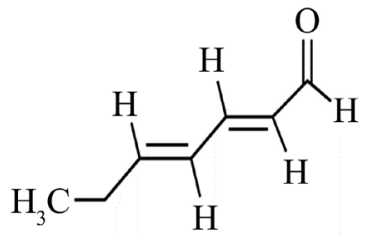

2-trans, 4-trans heptadienal

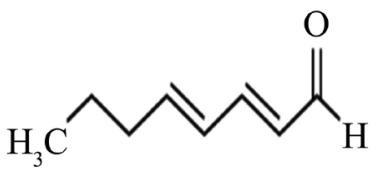

2-trans, 4-trans octadienal

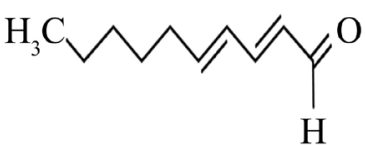

2-trans, 4-trans decadienal

Figure 1. Chemical structures of studied diatom-derived molecules such as 2-trans, 4-trans heptadienal, 2-trans, 4-trans octadienal and 2-trans, 4-trans decadienal. 


\section{Materials and Methods}

\subsection{Experimental Animals}

Eggs of the mosquito Ae. aegypti were collected from Ecosystem Research Laboratory, Acharya Narendra Dev College, University of Delhi, New Delhi. After that, the eggs were transferred to a plastic tray after coming back to the laboratory (sized $12 \times 16 \times 3$ inches) for hatching that contained $1000 \mathrm{~mL}$ of tap water. All larval stages were fed on the mixture of pedigree dog biscuits and yeast extract (3:2). Mosquito larvae of instar-I and instar-IV were used for the experiment.

\subsection{Test Solutions}

Pure chemicals of diatom, poly-unsaturated-aldehydes (PUAs), i.e. 2-trans,4-trans-decadienal (DD) $\left[\mathrm{C}_{10} \mathrm{H}_{16} \mathrm{O}\right]$, 2-trans,4-trans-octadienal (OD) $\left[\mathrm{C}_{8} \mathrm{H}_{12} \mathrm{O}\right]$ and 2-trans,4-trans-heptadienal (HD) $\left[\mathrm{C}_{6} \mathrm{H}_{8} \mathrm{O}\right]$ were procured from SIGMA Aldrich. Stock solution of $100 \mathrm{mg} \cdot \mathrm{mL}^{-1}$ of each PUA was prepared in Autoclaved Tap Water (ATW) from the original chemical. Thereafter, desirable concentrations were taken from the stock solution and further dilutions were prepared for the experiment. Test concentrations of HD, OD, and DD are provided in Table 1 and Table 2.

\subsection{Experimental Protocol}

The study was conducted in National Taiwan Ocean University, Taiwan. Ten larvae of each instar (I and IV) of Ae. aegypti were picked up by glass dropper and transferred individually into respective bowls containing one of the test concentrations. Four replicates were used for each concentration. Larval mortalities were recorded after $0.5,1,3,6,9,12$ and $24 \mathrm{~h}$ experimental period. $60 \mathrm{~mL}$ sized bowls containing $40 \mathrm{~mL}$ medium were used for every replicate. Control (without any PUA) was set up in autoclaved tap water. Abbott's formula was used to correct the mortalities recorded in the control [36].

Table 1. Percent mortality (mean $\pm \mathrm{SE}$ ) of Aedes aegypti larval instar-I to algal toxins, i.e. $\mathrm{HD}=$ heptadienal, $\mathrm{OD}=$ octadienal, $\mathrm{DD}=$ decadienal $($ after $12 \mathrm{~h}$ and $24 \mathrm{~h}$ ).

\begin{tabular}{ccccccc}
\hline \multirow{2}{*}{$\begin{array}{c}\text { Concentration } \\
(\mu \mathrm{l} / 40 \mathrm{ml})\end{array}$} & \multicolumn{3}{c}{ After $12 \mathrm{~h}$} & \multicolumn{3}{c}{ After $24 \mathrm{~h}$} \\
\cline { 2 - 7 } & HD & OD & DD & HD & OD & DD \\
\hline $\mathbf{0 . 1 0 2 5}$ & $0 \pm 0$ & $0 \pm 0$ & $0 \pm 0$ & $0 \pm 0$ & $0 \pm 0$ & $0 \pm 0$ \\
$\mathbf{0 . 2 0 5}$ & $0 \pm 0$ & $0 \pm 0$ & $6.67 \pm 6.67$ & $0 \pm 0$ & $0 \pm 0$ & $6.67 \pm 6.67$ \\
$\mathbf{0 . 4 1}$ & $0 \pm 0$ & $0 \pm 0$ & $23.33 \pm 3.33$ & $0 \pm 0$ & $0 \pm 0$ & 23.33 \\
$\mathbf{0 . 8 2}$ & $6.67 \pm 6.67$ & $16.67 \pm 3.33$ & $70 \pm 5.77$ & $30 \pm 10$ & $46.67 \pm 3.33$ & 73.33 \\
$\mathbf{1 . 6 4}$ & $66.66 \pm 3.33$ & $63.33 \pm 3.33$ & $90 \pm 5.77$ & $66.67 \pm 6.67$ & $100 \pm 0$ & $100 \pm 0$ \\
3.28 & $96.67 \pm 3.33$ & $100 \pm 0$ & $100 \pm 0$ & $96.67 \pm 3.33$ & $100 \pm 0$ & $100 \pm 0$ \\
6.56 & $100 \pm 0$ & $100 \pm 0$ & $100 \pm 0$ & $100 \pm 0$ & $100 \pm 0$ & $100 \pm 0$ \\
\hline
\end{tabular}


Table 2. Percent mortality (mean $\pm \mathrm{SE}$ ) of Aedes aegypti larval instar-IV to algal toxins, i.e. $\mathrm{HD}=$ heptadienal, $\mathrm{OD}=$ octadienal, $\mathrm{DD}=$ decadienal (after $12 \mathrm{~h}$ and $24 \mathrm{~h}$ ).

\begin{tabular}{|c|c|c|c|c|c|c|}
\hline \multirow{2}{*}{$\begin{array}{l}\text { Concentration } \\
(\mu \mathrm{l} / 40 \mathrm{~mL})\end{array}$} & \multicolumn{3}{|c|}{ After $12 \mathrm{~h}$} & \multicolumn{3}{|c|}{ After $24 \mathrm{~h}$} \\
\hline & HD & OD & DD & HD & OD & $\mathrm{DD}$ \\
\hline 0.1025 & $0 \pm 0$ & $0 \pm 0$ & $0 \pm 0$ & $0 \pm 0$ & $0 \pm 0$ & $0 \pm 0$ \\
\hline 0.205 & $0 \pm 0$ & $0 \pm 0$ & $0 \pm 0$ & $0 \pm 0$ & $0 \pm 0$ & $0 \pm 0$ \\
\hline 0.41 & $0 \pm 0$ & $0 \pm 0$ & $0 \pm 0$ & $0 \pm 0$ & $0 \pm 0$ & $0 \pm 0$ \\
\hline 0.82 & $0 \pm 0$ & $0 \pm 0$ & $0 \pm 0$ & $0 \pm 0$ & $0 \pm 0$ & $0 \pm 0$ \\
\hline 1.64 & $0 \pm 0$ & $0 \pm 0$ & $0 \pm 0$ & $0 \pm 0$ & $0 \pm 0$ & $0 \pm 0$ \\
\hline 3.28 & $10 \pm 5.77$ & $30 \pm 10$ & $43.33 \pm 3.33$ & $16.67 \pm 3.33$ & $37.67 \pm 8.81$ & $43.33 \pm 3.33$ \\
\hline 6.56 & $40 \pm 0$ & $53.33 \pm 3.33$ & $63.33 \pm 3.33$ & 43.33 & $56.67 \pm 3.33$ & $63.33 \pm 3.33$ \\
\hline 13.12 & $50 \pm 1.52$ & $76 \pm 5.78$ & $76.67 \pm 3.33$ & $50 \pm 1.52$ & $76 \pm 5.77$ & $76.67 \pm 3.33$ \\
\hline 26.24 & $90 \pm 5.77$ & $100 \pm 0$ & $100 \pm 0$ & $90 \pm 5.77$ & $100 \pm 0$ & $100 \pm 0$ \\
\hline 52.48 & $93.33 \pm 3.33$ & $100 \pm 0$ & $100 \pm 0$ & $100 \pm 0$ & $100 \pm 0$ & $100 \pm 0$ \\
\hline
\end{tabular}

Corrected mortality

$=\frac{\text { Observed mortality in treatments }- \text { observed mortality in control }}{100-\text { Control mortality }} \times 100$

Percentage mortality $=\frac{\text { Number of dead larvae }}{\text { Number of larvae introduced }} \times 100$

\subsection{Statistical Analysis}

The arc sine transformed data of percent mortality were used for statistical analyses. A probit regression was used to estimate dose specific mortality of larvae for each aldehyde. A two factor ANOVA was applied to determine differences among chemicals and concentrations. SPSS statistical software (SPSS statistics 18.0) was used to perform the statistical analyses.

\section{Results}

Details of percent mortalities of Ae. aegypti larvae Instar-I and -IV to different concentrations of HD, OD and DD are provided in Table 1 and Table 2, respectively. We observed the significantly $(p<0.05)$ higher susceptibility of $A e$. aegypti larvae Instar-I to HD, OD and DD compared to instar-IV immatures. A range of concentrations from 0.1025 to $6.56 \mu \mathrm{L} / 40 \mathrm{~mL}$ of $\mathrm{HD}$, OD and DD was tested on different instars of the mosquito Ae. aegypti. Out of the tested range of concentrations, $6.67 \%$ and $23.33 \%$ instar-I larvae died at $0.205 \mu \mathrm{L}$ and $0.41 \mu \mathrm{L}$ respectively of DD treatment after a $12 \mathrm{~h}$ period. However, same concentration did not exert any influence on instar-I larvae after HD and OD treatment. An average of $70 \%$ mortality was recorded for instar-I larvae at $0.82 \mu \mathrm{L}$ concentration of DD treatment, whereas only $6.67 \%$ and $16.67 \%$ mortality was observed at $\mathrm{HD}$ and $\mathrm{OD}$ treatments respectively, after $12 \mathrm{~h}$ experimental duration. The OD and DD recorded $100 \%$ mortality of instar-I larvae at $3.28 \mu \mathrm{L}$. However, after 12 
h exposure, 96.67\% larval mortality of instar-I larvae was recorded with the same concentration of HD treatment within the same time period (Table 1 and Figure 2).

On the other hand, when the larvae were treated with all three PUAs for an experimental period of $24 \mathrm{~h}$, it was noted that all instar-I larvae died at $1.64 \mu \mathrm{L}$ concentration of OD and DD, whereas only $66.67 \%$ of instar-I larvae died upon HD treatment. A mortality of $30 \%$ of instar-I larvae was recorded at $0.82 \mu \mathrm{L}$ concentration of HD treatment. However, $46.67 \%$ and $73.33 \%$ larvae were dead after $24 \mathrm{~h}$ of exposure of OD and DD treatments, respectively.
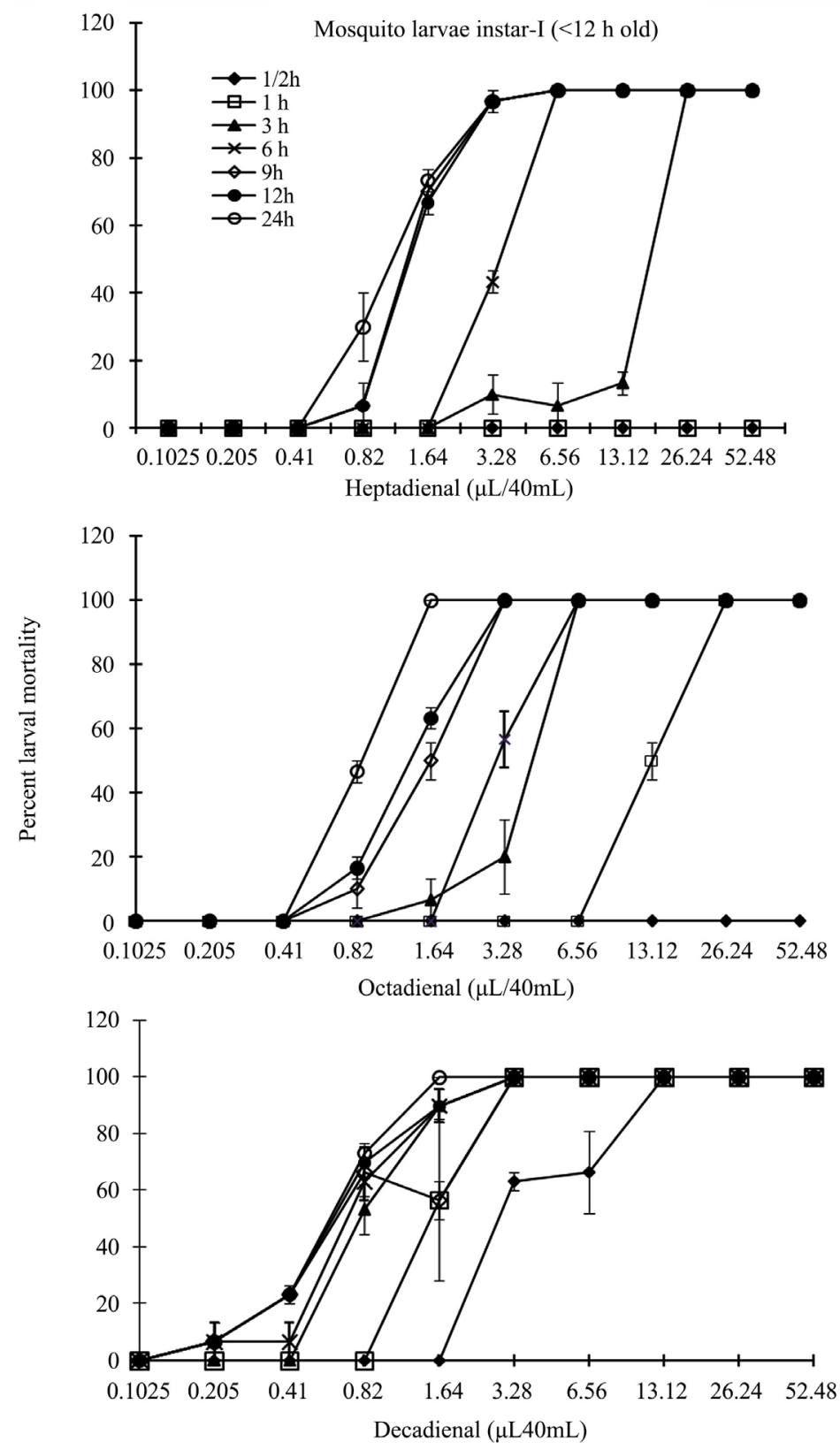

Figure 2. Percent larval mortality of instar-I of Aedes aegypti to algal PUAs, heptadienal, octadienal, decadienal (after different time intervals). 
Similarly, a range of concentrations such as from 0.10 to $52.48 \mu \mathrm{L}$ of $\mathrm{HD}, \mathrm{OD}$ and DD were tested separately against instar-IV larvae (Table 2 and Figure 3). After an exposure of $12 \mathrm{~h}$, all larvae were dead in OD and DD treatments with $26.24 \mu \mathrm{L}$, whereas at same concentration and exposure duration $10 \%$ of Instar-IV larvae were alive in HD treatment. No significant difference in instar-IV larval mortality was noted among 26.24 to $52.48 \mu \mathrm{L}$ concentrations of HD treatment after $24 \mathrm{~h}$ exposure. On one hand, $10 \%$ of instar-IV larval mortality was recorded at $3.28 \mu \mathrm{L}$ of HD treatment. However, $30 \%$ and $43.33 \%$ mortality of instar-IV larvae were recorded at OD and DD treatments. A proportion of $76.67 \%$ of instar-IV larvae died at $13.12 \mu \mathrm{L}$ upon DD treatment. However, 50 and $76 \%$ instar-IV larval mortality was recorded upon HD and OD treatments, respectively. Complete mortality of larvae was observed at $26.24 \mu \mathrm{L}$ of OD and DD concentration after $24 \mathrm{~h}$ of exposure, whereas $90 \%$ larvae died at the same concentration of HD treatment (Table 1 and Figure 2).
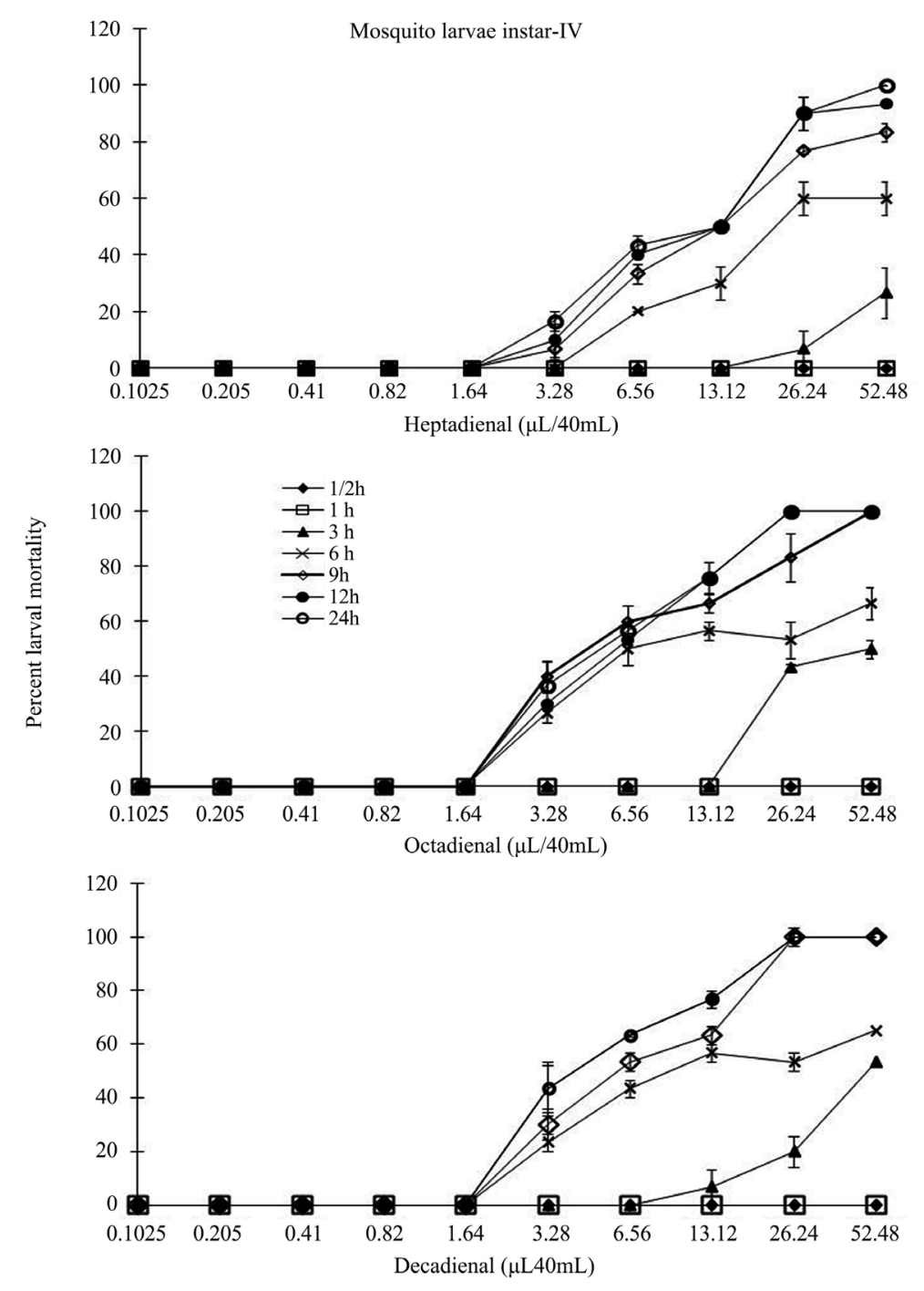

Figure 3. Percent larval mortality of instar-IV of Aedes aegyptito algal PUAs, heptadienal, octadienal, decadienal (after different time interval). 
Table 3 and Table 4 illustrate the probit analyzed, LC 50 and LC99 values of instar-I and -IV larval mortality after the treatment with HD, OD, and DD after $12 \mathrm{~h}$ and $24 \mathrm{~h}$ observation. LC50 and LC99 values were 1.55 and $2.86 \mu \mathrm{L}$ upon HD treatment, 1.44 and $2.58 \mu \mathrm{L}$ upon OD treatment and 0.080 and $1.89 \mu \mathrm{L}$ upon DD treatment, respectively, after $12 \mathrm{~h}$ of observation. On the other hand, LC50 values for instar-I larvae were 1.47, 0.88 and $0.64 \mu \mathrm{L}$ upon $\mathrm{HD}$, OD, and DD treatment, respectively, after $24 \mathrm{~h}$ observation. Furthermore, LC99 values for instar-I larvae were 3.04, 1.46 and $1.26 \mu \mathrm{L}$ upon $\mathrm{HD}, \mathrm{OD}$, and DD, respectively, after $24 \mathrm{~h}$ exposure. LC50 values for instar-IV larvae were 17.76, 8.71 and 7.50 $\mu \mathrm{L}$ upon $\mathrm{HD}, \mathrm{OD}$ and $\mathrm{DD}$, respectively, after $12 \mathrm{~h}$ exposure. However, LC50 values for instar-IV larvae were 13.37, 8.43 and $7.54 \mu \mathrm{L}$ upon $\mathrm{HD}$, OD, and DD exposure for $24 \mathrm{~h}$. LC99 values for instar-IV larvae were 44.18, 19.44 and 17.49 $\mu \mathrm{L}$ upon $\mathrm{HD}, \mathrm{OD}$ and DD exposure, respectively, after $12 \mathrm{~h}$ exposure. LC99 values for instar-IV larvae were 30.76, 19.31 and $17.49 \mu \mathrm{L}$ upon $\mathrm{HD}$, OD, and DD, respectively, after $24 \mathrm{~h}$ exposure.

Table 3. Toxicity effect of diatom aldehydes against larval instar-I of Aedes aegypti.

\begin{tabular}{ccccc}
\hline $\begin{array}{c}\text { Observation } \\
\text { time }\end{array}$ & $\begin{array}{c}\text { Diatom } \\
\text { aldehydes }\end{array}$ & LC50 (LFL-UFL) & LC99 (LFL-UFL) & $\chi^{2}(\mathrm{df}=5)$ \\
\hline & HD & $1.55(0.75-10.86)$ & $2.86(1.93-48.92)$ & $114.95^{\star}$ \\
12 & OD & $1.44(1.34-1.55)$ & $2.58(2.37-2.89)$ & 7.22 n.s. \\
& DD & $0.080(0.57-1.14)$ & $1.89(1.43-3.18)$ & $34.23^{\star}$ \\
& HD & $1.47(1.037-2.37)$ & $3.04(2.2-6.15)$ & $50.07^{\star}$ \\
& OD & $0.88(0.83-0.96)$ & $1.46(1.31-1.70)$ & 5.45 n.s. \\
& DD & $0.64(0.59-0.69)$ & $1.26(1.14-1.42)$ & 3.64 n.s. \\
\hline
\end{tabular}

HD-2-trans,4-trans heptadienal, OD- 2-trans,4-trans octadienal, DD-2-trans, 4-trans decadienal (DD), LFL-lower fiducial limit, UFL-upper fiducial limit, LC50-lethal concentration that kills 50\% of the exposed larvae, LC99-lethal concentration that kills $99 \%$ of the exposed larvae, $\chi^{2}$-Chi square value, *Significant at $p<0.05$ level, n.s. $=$ not significant.

Table 4. Toxicity effect of diatom aldehydes against larval instar-IV of Aedes aegypti.

\begin{tabular}{ccccc}
\hline $\begin{array}{c}\text { Observation } \\
\text { time }\end{array}$ & $\begin{array}{c}\text { Diatom } \\
\text { aldehydes }\end{array}$ & LC50 (LFL-UFL) & LC99 (LFL-UFL) & $\chi^{2}(\mathrm{df}=\mathbf{8})$ \\
\hline & HD & $17.76(14.56-22.46)$ & $44.18(32.14-66.68)$ & $482.33^{*}$ \\
12 & OD & $8.71(6.42-13.04)$ & $19.44(14.49-32.91)$ & $85.34^{*}$ \\
& DD & $7.55(5.09-12.68)$ & $17.49(12.46-34.55)$ & $127.20^{*}$ \\
& HD & $13.37(9.84-19.78)$ & $30.76(23.05-49.99)$ & $81.8^{*}$ \\
& OD & $8.43(5.91-13.72)$ & $19.31(13.93-37.51)$ & $108.37^{*}$ \\
& DD & $7.54(5.09-12.68)$ & $17.49(12.46-34.55)$ & $127.20^{*}$ \\
\hline
\end{tabular}

HD-2-trans,4-trans heptadienal, OD-2-trans,4-trans octadienal, DD-2-trans, 4-trans decadienal (DD), LFL-lower fiducial limit, UFL-upper fiducial limit, LC50-lethal concentration that kills $50 \%$ of the exposed larvae, LC99-lethal concentration that kills $99 \%$ of the exposed larvae, $\chi^{2}-$ Chi square value. * Significant at $p<0.05$ level. 


\section{Discussion}

The yellow fever mosquito, Aedes aegypti, originating from Africa is the vector transmitting several fatal diseases such as dengue fever, zika fever, chikungunya, and yellow fever [37]. Ae. aegypti is meanwhile widely distributed in tropical and subtropical regions worldwide. According to recently published data by the WHO, about half of the world's human population is at high risk of Dengue fever infection. Approximately, 3.9 billion people are infected by the dengue virus in 128 countries across the world [38] [39]. The WHO has highlighted India as a highly risk prone dengue fever area recording over 15,000 cases in 2015. Still, no proper treatment is available against Dengue. Multiple strategies such as insecticides, microbicides, herbicides are explored as biocontrol agents of vector borne diseases and are frequently used in combating diseases transmitted by mosquitoes [8] [37] [40] [41]. Our results showed significant mortality effects of natural bioactive substances such as PUAs on mosquito immatures. This is quite evidenced by plant based extracts as well as algal extracts [37]. There are about 1200 plant species which exhibit larvicidal properties [42].

Further comprehensive information are provided by Shaalan et al. [22] and Benelli [37] on mosquitocidal properties of different plant species. These authors have emphasized the inhibitory effects of plant metabolites on growth and reproduction. However, the published information on adverse effects of algal aldehydes on mosquitoes is very limited.

Dhanker et al. [40] found that approximately $50 \%$ instar-I and late instars of Ae. aegypti died at $5 \times 10^{-5} \mu \mathrm{L}^{-1}$ and $5 \times 10^{-3} \mu \mathrm{L}^{-1}$ upon Bti treatment (Bacillus thuringiensis var. israelensis). Similarly, temephos a commonly used pesticide for mosquito control programs, was able to kill $50 \%$ and $100 \%$ larvae at concentrations of $25 \times 10^{-3} \mu \mathrm{L}^{-1}$ and $2.5 \mu \mathrm{L}^{-1}$ tested against instar-I and late instar-II [40]. However, considerable evidence indicated resistance of mosquitoes to these insecticides [43]. As a result, several alternative and environment friendly strategies have emerged as potential control mechanisms [8] [41] [44].

Our results confirmed that diatom aldehydes toxicity depends on larval age and is dose dependent. The initial concentrations which were toxic for I instar larvae did not exert any mortality in IV instar larvae. The concentration $3.28 \mu \mathrm{L}$ at which approximately $100 \%$ I instar larvae died, only less that $50 \%$ IV instar larvae died. The larval age and dose dependant toxicity in mosquito larvae has also been confirmed by numerous previously published references by applying other biocontrol methods such as phytochemicals [8], pure leaf extracts [41] and other insecticides [40].

The larvicidal and pupicidal efficiency of leaf extracts of Carica papaya was tested against all developmental stages (I to IV instar) and pupae of Ae. aegypti by Kovendan et al. [41]. The leaf extract prepared in methanol showed the highest toxic effect on all larval stages and pupae. According to authors, the LC50 values were $51.76 \mathrm{ppm}$ and $82.18 \mathrm{ppm}$ for I and IV instars of larvae, respectively. In our previous study, the mosquito larvicidal efficiency of phytochemicals such 
as eugenol and piperine were tested against I and late instar-II of Ae aegypti immatures. Different concentrations of eugenol $\left(0.5\right.$ to $\left.8000 \mathrm{~mL}^{-1}\right)$ and piperine ( 0.05 to $\left.3000 \mathrm{mg} \cdot \mathrm{L}^{-1}\right)$ were tested on larvae. It was noted that in piperine applied medium, the LC50 value of instar I was $15.28 \mathrm{mg} \cdot \mathrm{L}^{-1}$, the late II instar was 29.89 $\mathrm{mg} \cdot \mathrm{L}^{-1}$. Similarly, in eugenol applied medium, the LC50 value of the instar-I was $272.74 \mathrm{mg} \cdot \mathrm{L}^{-1}$, late II instar was $453.67 \mathrm{mg} \cdot \mathrm{L}^{-1}$. In our present results, LC50 values for instar-I larvae were 1.47, 0.64 and 0.88 for HD, OD and DD PUAs, respectively, and LC50 values for instar-IV larvae were 17.76, 7.5 and 8.71 on HD, OD and DD PUAs, respectively, after $24 \mathrm{~h}$ of exposure.

Our tests confirmed that Ae. aegypti larvae were susceptible to diatom PUAs. PUA DD were found more toxic compared to OD and HD. Higher toxicity of DD was confirmed by several previous studies in several invertebrates [23] [24]. Furthermore, instar-I larvae were more susceptible to all tested PUAs, which was also in agreement with other studies testing mosquito susceptibility with pesticides and phytochemicals [8] [40]. Algae are found in most moist places from aquatic to terrestrial, and are even recorded from deserts [45]. Bioactive compounds either extracted from their biomass or secreted by the algae to their ambient envrionment against predators, competitors, and pathogens are well investigated [24].

\section{Conclusion}

Our present results demonstrate that all three tested pure extracts of diatom aldehydes, PUAs, have shown larvicidal activities against the Dengue causing vector, Ae. aegypti which is a highly targeted species of vector control programs. PUA's may provide as yet unstudied means of eco-friendly biocontrol measures against mosquito larvae. The present study has targeted different developmental stages of mosquitoes against PUAs, i.e. $\mathrm{HD}, \mathrm{OD}$, and $\mathrm{DD}$, on the survival of different aged mosquito larvae at laboratory scale. Diatom PUAs eradicate Ae. aegypti larvae. However, the present results need to be confirmed at a larger scale with trials in outdoor ecosystems in diverse ecological and evolutionary frameworks to obtain more thorough and reliable information about combined effects of algae and their primary consumers. However, further research is needed on the ecological impact of these algal chemicals in the environment. The present results open up possibilities to utilize these aldehydes as larvicides but also as amendments to personal care products, such as mosquito repellents, as ointment or spray to deter or kill adult mosquitoes. Utilization of natural phytochemical extracts in controlling mosquito vectors may provide a safe and sustainable solution, particularly for tropical and subtropical countries globally. However, in order to use PUAs as an alternative for vector control, more information regarding its influence on other aquatic organisms are needed.

\section{Acknowledgements}

We acknowledge Dr. Samba Ka for helping during the experiment. We thank 
Ravi Kumar for their assistance in mosquito culture. Raunak thanks National Science Council of Taiwan for financial support (NSC 98-2621-B-019-001-MY) and NTOU, Taiwan for a Ph. D. scholarship.

\section{Conflicts of Interest}

The authors declare no conflicts of interest regarding the publication of this paper.

\section{References}

[1] Teixeira Mda, G., Mda-Costa, C., Barreto, M.L. and Mota, E. (2005) Dengue and Dengue Hemorrhagic Fever Epidemics in Brazil: What Research Is Needed Based on Trends, Surveillance, and Control Experiences? Cadernos de Saúde Pública, 21, 1307-1315. https://doi.org/10.1590/S0102-311X2005000500002

[2] Bhatt, S., Gething, P.W., Brady, O.J., Messina, J.P., Farlow, A.W., Moyes, C.L., Drake, J.M., Brownstein, J.S., Hoen, A.G., Sankoh, O., Myers, M.F., George, D.B., Jaenisch, T., Wint, G.R., Simmons, C.P., Scott, T.W., Farrar, J.J. and Hay, S.I. (2013) The Global Distribution and Burden of Dengue. Nature, 496, 504-507.

[3] Harrington, L.C., Scott, T.W. and Lerdthusnee, K. (2005) Dispersal of the dengue vector Aedes aegypti within and between rural communities. American Journal of Tropical Medical Hygiene, 72, 209-220. https://doi.org/10.4269/ajtmh.2005.72.209

[4] Madzlana, F., Doma, N.C., Tiongb, C.S. and Zakaria, N. (2016) Breeding Characteristics of Aedes Mosquitoes in Dengue Risk Area. Procedia-Social Behavioral Science, 234, 164-172. https://doi.org/10.1016/j.sbspro.2016.10.231

[5] Faiz, M., Nazri, C.D. and Chua, S.T. (2017) Spatial and Temporal Distribution of Aedes (Diptera: Culicidae) Mosquitoes in Shah Alam. Tropical Biomedical, 34, 1-9.

[6] Awasthi, A.K., Wu C.H., Tsai K.H., King C.C. and Hwang J.S. (2012) How Does Ambush Predatory Copepod Megacyclops formosanus (Harada 1931) Capture Mosquito Larvae, Aedes aegypti? Zoological Studies, 51, 927-937.

[7] Kalimuthu, K., Panneerselvam, C., Murugan, K. and Hwang, J.S. (2013) Green Synthesis of Silver Nanoparticles Using Cadaba indica Lam Leaf Extract and Its Larvicidal and Pupicidal Activity against Anopheles stephensi and Culex quinquefasciatus. Journal of Entomology Acarol Research, 45, e11.

https://doi.org/10.4081/jear.2013.e11

[8] Dhanker, R., Kumar, R. and Hwang, J.S. (2013) How Effective Are Mesocyclops aspericornis (Copepoda: Cyclopoida) in Controlling Mosquito Immatures in the Environment with an Application of Phytochemicals? Hydrobiologia, 716, 147-162. https://doi.org/10.1007/s10750-013-1559-9

[9] Gratz, N.G. (1999) Emerging and Resurging Vector-Borne Diseases. Annual Review of Entomology, 44, 51-75. https://doi.org/10.1146/annurev.ento.44.1.51

[10] Lardeux, F., Riviere, F., Sechan, Y. and Loucke, S. (2002) Control of the Aedes Vector of the Dengue Viruses and Wuchereria bancrofti: The French Polynesian Experience. Annual Tropical Medical Parasitology, 96, 105-116. https://doi.org/10.1179/000349802125002455

[11] Rao, D.R., Reuben, R. and Nagasampagi, B.A. (1995) Development of Combined Use of Neem (Azadirachta indica) and Water Management for the Control of Culicine Mosquitoes in Rice Fields. Medical Vet Entomology, 9, 25-33. https://doi.org/10.1111/j.1365-2915.1995.tb00113.x 
[12] Rao, D.R., Mani, T.R., Rajendran, R., Joseph, A.S., Gjanana, A. and Reuben, R. (1995) Development of High Level of Resistance to Bacillus sphaericus in a Field Population of Culex quinquifasciatus from Kochi, India. Journal of American Mosquito Control Association, 11, 1-5.

[13] Kumar, R. and Hwang, J.S. (2006) Larvicidal Efficiency of Aquatic Predators: A Perspective for Mosquito Biocontrol. Zoological Studies, 45, 447-466.

[14] Dhanker, R., Kumar, R. and Hwang, J.S. (2012) Predation by Pseudodiaptomus annandalei (Copepoda: Calanoida) on Rotifer Prey: Size Selection, Egg Predation and Effect of Algal Diet. Journal of Experimental Marine Biology and Ecology, 414-415, 44-53. https://doi.org/10.1016/j.jembe.2012.01.011

[15] Dhanker, R., Kumar, R., Tseng, L.C. and Hwang, J.S. (2013b) Ciliate (Euplotes sp.) Predation by Pseudodiaptomus annandalei (Copepoda: Calanoida) and the Effects of Mono-Algal and Pluri-Algal Diets. Zoological Studies, 52, 34.

https://doi.org/10.1186/1810-522X-52-34

[16] Lundholm, N., Krock, B., John, U., Skov, J., Cheng, J., Pancic, M., Wohlrab, S., Rigby, K., Nielsen, T.G., Selander, E. and Haroardottir, S. (2018) Induction of Domoic Acid Production in Diatoms-Types of Grazers and Diatoms Are Important. Harmful Algae, 79, 64-73. https://doi.org/10.1016/j.hal.2018.06.005

[17] Legendre, L. (1990) The Significance of Microalgal Blooms for Fisheries and for the Export of Particulate Organic Carbon in Oceans. Journal of Plankton Research, 12, 681-699. https://doi.org/10.1093/plankt/12.4.681

[18] Marten, G.G. and Reid, J.W. (2007) Cyclopoid Copepods. Journal of American Mosquito Control Association, 23, 65-92. https://doi.org/10.2987/8756-971X(2007)23[65:CC]2.0.CO;2

[19] Caldwell, G.S. (2009) The Influence of Bioactive Oxylipins from Marine Diatoms on Invertebrate Reproduction and Development. Marine Drugs, 7, 377-400. https://doi.org/10.3390/md7030367

[20] Chansang Bhumiratana, U.A. and Kittayapong, P. (2004) Combination of Mesocyclops thermocyclopoides and Bacillus thuringiensis var. israelensis. A Better Approach for the Control of Aedes aegypti Larvae in Water Containers. Journal of Vector Ecology, 29, 218-226.

[21] Jahan, A., Ahmad, I.Z., Fatima, N., Ansari, V.A. and Akhtar, J. (2017) Algal Bioactive Compounds in the Cosmeceutical Industry: A Review. Phycologia, 56, 410-422. https://doi.org/10.2216/15.58.1

[22] Ianora, A., Romano, G., Carotenuto, Y., Esposito, F., Roncalli, V., Buttino, I. and Miralto, A. (2011) Impact of the Diatom Oxylipin 15S-HEPE on the Reproductive Success of the Copepod Temora stylifera. Hydrobiologia, 666, 265-275. https://doi.org/10.1007/s10750-010-0420-7

[23] Shaalan, E.A., Canyon, D., Younes, M.W., Abdel-Wahab. H. and Mansour, A.H. (2005) A Review of Botanical Phytochemicals with Mosquitocidal Potential. Environment International, 31, 1149-1166. https://doi.org/10.1016/j.envint.2005.03.003

[24] Ianora, A. and Miralto, A. (2010) Toxigenic Effects of Diatoms on Grazers, Phytoplankton and Other Microbes: A Review. Ecotoxicology, 19, 493-511. https://doi.org/10.1007/s10646-009-0434-y

[25] Vidoudez, C., Casotti, R., Bastianini, M. and Pohnert, G. (2011) Quantification of Dissolved and Particulate Polyunsaturated Aldehydes in the Adriatic Sea. Marine Drugs, 9, 500-513. https://doi.org/10.3390/md9040500

[26] Harada, K., Suomalainen, M., Uchida, H., Masui, H., Ohmura, K., Kiviranta, J., Niku-Paavola, M.L. and Ikemoto, T. (2000) Insecticidal Compounds against Mosquito 
Larvae form Oscillatoria agardhii Strain 27. Environmental Toxicology, 15, 114-119. https://doi.org/10.1002/(SICI)1522-7278(2000)15:2<114::AID-TOX7>3.0.CO;2-P

[27] Grane'li, E. and Hansen, P.J. (2006) Allelopathy in harmful algae: a mechanism to compete for resources? In: Granéli, E. and Turner, J.T., Eds., Ecology of Harmful Algae, Ecological Studies, Springer-Verlag, Berlin, Heidelberg, Germany.

[28] Wendel, T. and Jüttner, F. (1996) Lipoxygenase-Mediated Formation of Hydrocarbons and Unsaturated Aldehydes in Freshwater Diatoms. Phytochemistry, 41, 1445-1449. https://doi.org/10.1016/0031-9422(95)00828-4

[29] Miralto, A., Barone, G., Romano, G., Poulet, S.A., Ianora, A., Russo, G.L., Buttino, I., Mazzarella, G., Laabir, M., Cabrini, M. and Giacobbbe, M.G. (1999) The Insidious Effect of Diatoms on Copepod Reproduction. Nature, 402, 173-176. https://doi.org/10.1038/46023

[30] Adolph, S., Bach, S., Blondel, M., Cueff, A., Moreau, M., Pohnert, G. and Poulet, S.A. (2004) Cytoxicity of Diatom-Derived Oxylipins in Organisms Belonging to Different Phyla. Journal of Experimental Biology, 207, 2935-2946. https://doi.org/10.1242/jeb.01105

[31] Carotenuto, Y., Ianora, A., Buttino, I., Romano, G. and Miralto, A. (2002) Is Postembryonic Development in the Copepod Temora stylifera Negatively Affected by Diatom Diets? Journal of Experimental Marine Biology and Ecology, 276, 49-66. https://doi.org/10.1016/S0022-0981(02)00237-X

[32] Ianora, A., Miralto, A., Poulet, S.A., Carotenuto, Y., Buttino, I., Romano, G., Casotti, R., Pohnert, G., Wichard, T., Colucci-D’Amato, L., Terrazzano, G. and Smetacek, V. (2004) Aldehyde Suppression of Copepod Recruitment in Blooms of a Ubiquitous Planktonic Diatom. Nature, 429, 403-407. https://doi.org/10.1038/nature02526

[33] Buttino, I., De Rosa, G., Carotenuto, Y., Mazzela, M., Ianora, A., Esposito, F., Vitiello, V., Quaglia, F., La Rotonda, M.I. and Miralto, A. (2008) Aldehyde-Encapsulating Liposomes Impair Marine Grazer Survivorship. Journal of $E_{X^{-}}$ perimental Biology, 211, 1426-1433. https://doi.org/10.1242/jeb.015859

[34] Dhanker, R., Molinero, J.C., Kumar, R., Tseng, L.C., Ianora, A. and Hwang, J.S. (2015) Responses of the Estuarine Copepod Pseudodiaptomus annandalei to Diatom Polyunsaturated Aldehydes: Reproduction, Survival and Postembryonic Development. Harmful Algae, 43, 74-81. https://doi.org/10.1016/j.hal.2015.02.002

[35] Rey, J.R., Hargraves, P.E. and O'Connell, S.M. (2009) Effect of Selected Marine and Freshwater Microalgae on Development and Survival of the Mosquito Aedes aegypti. Aquatic Ecology, 43, 987-997. https://doi.org/10.1007/s10452-009-9232-0

[36] Abbott, W.S. (1925) A Method of Computing the Effectiveness of Insecticides. Journal of Ecology and Entomology, 18, 267-269. https://doi.org/10.1093/jee/18.2.265a

[37] Benelli, G. (2015) Research in Mosquito Control: Current Challenges for a Brighter Future. Parasitology Research, 114, 2801-2805.

https://doi.org/10.1007/s00436-015-4586-9

[38] Brady, O.J., Gething, P.W., Bhatt, S., Messina, J.P., Brownstein, J.S., Hoen, A.G., Moyes, C.L., Farlow, A.W., Scott, T.W. and Hay, S.I. (2012) Refining the Global Spatial Limits of Dengue Virus Transmission by Evidence-Based Consensus. PLoS Neglected Tropical Disease, 6, e1760. https://doi.org/10.1371/journal.pntd.0001760

[39] World Health Organization (2018) Dengue Control Epidemiology Fact Sheet. World Health Organization, Geneva. https://www.who.int/en/news-room/factsheets/detail/dengue-and-severe-dengue

[40] Dhanker, R., Kumar, R. and Raghvendra, K. (2014) Efficiency of Copepods to Con- 
trol Aedes aegypti Larvae in Medium Applied with Insecticides (Bti and Temephos), In: Kumar, R., Ed., Climate Change, Aquatic Community Structure and Disease, Proceedings of the National Symposium on Biodiversity, Biotechnology and Man: Interdependence and Future Challenges, Ilavart Publication, Delhi, India.

[41] Kovendan, K., Murugan, K., Naresh, A.K., Vincent, S. and Hwang, J.S. (2012) Bio-Efficacy of Larvicidal and Pupicidal Properties of Carica papaya (Caricaceae) Leaf Extract and Bacterial Insecticide, Spinosad against Chikungunya Vector, Aedes aegypti (Diptera: Culicidae). Parasitology Researh, 110, 669-678.

https://doi.org/10.1007/s00436-011-2540-z

[42] Roark, R.C. (1947) Some Promising Insecticidal Plants. Economic Botany, 1, 437-445. https://doi.org/10.1007/BF02858908

[43] Liu, N. (2015) Insecticide Resistance in Mosquitoes: Impact, Mechanisms, and Research Directions. Annual Review of Entomology, 60, 537-559.

https://doi.org/10.1146/annurev-ento-010814-020828

[44] Murugan, K., Che, J.S., Kovendan, K., Kumar, K.P., Vasugi, C. and Kumar, A.N. (2011) Use of Plant Products and Copepods for Control of the Dengue Vector, Aedes aegypti. Hydrobiologia, 666, 331-338. https://doi.org/10.1007/s10750-011-0629-0

[45] Mann, D.G. and Droop, S.J.M. (1996) Biodiversity, Biogeography and Conservation of Diatoms. Hydrobiologia, 337, 19-32. https://doi.org/10.1007/BF00010816 